\section{A IMAGEM FOTOGRÁFICA COMO REPRESENTAÇÃO E DOCUMENTO: um estudo a partir das fotografias de objetos da sala de visitas do escritor Jorge Amado}

\section{Alzira Tude de Sá}

\begin{abstract}
Este é um estudo sobre a imagem como representação e documento, sua gênese, fabricação, suportes e usos, uma construção do homem para dar sentido ao real. Elege imagens fotográficas da casa do escritor Jorge Amado, como objeto, basicamente aquelas da sua sala de visitas, representações que podem apontar para as relações sociais e culturais construídas pelo escritor. A noção de documento como aporte teórico reporta-se ao conceito deBriet (I95I), ao pensamento de Buckland (I99I), Otlet (1996), Manini (20I I) como referências históricas de um novo pensar sobre sua materialidade. Reflete sobre a imagem como representação, seus modos de produção, usos e recepção. Busca identificar o percurso que fez com que a fotografía passasse de uma invenção do século XIX, com traços puramente estéticos de representação da realidade, para um instrumento de promoção e circulação social do conhecimento, ferramenta útil e eficaz da pesquisa acadêmica. A pesquisa caracteriza-se como exploratória, apropria-se do método heurístico, intuitivo e experimental, utiliza-se de questionário como instrumento de pesquisa e adota a observação direta do objeto. Como resultado, através da leitura, descrição, classificação e análise e de um processo de desmontagem e remontagem das imagens, aponta para a potencialidade da imagem fotográfica como fonte documental representativa das relações socioculturais estabelecidas pelo esctritor.
\end{abstract}

Palavras-chaves:Fotografia - Representação. Documento. Objetos - Representação. Jorge Amado.

\footnotetext{
* Doutora em Ciência da Informação pela Universidade Federal da Bahia, Brasil. Mestre em Letras pela Universidade do Estado da Bahia, Brasil. Professora Assistente do Instituto de Ciência da Informação da Universidade Federal da Bhia, Brasil.

E-mail: alziratude@gmail.com.
}

\section{INTRODUÇÃO}

P ara compreender a imagem fotográfica como imagen técnica, representação e documento é preciso que se reflita sobre os fatores socioculturais, ideológicos e históricos que vêm determinando os seus conceitos porque, numa homologia com a história, as imagens fotográficas estão diretamente relacionadas ao universo das ideias e das mentalidades que permeiam sua produção e trajetória.

Por vir do latim imago, a palavra imagem remete à representação de algo que se pode ver, que é retratado. No entanto, apesar dessa materialidade e visualidade, os efeitos produzidos nos sujeitos e no mundo não podem ser tratados de forma teórica ou abstrata. É preciso que sejamos auxiliados por um contexto empírico no qual se possam observar as escolhas, as percepções, seu impacto. Foi preciso, portanto, neste estudo, que elegêssemos um universo, um contexto empírico e que buscássemos compreender a ascensão da fotografia como documento social e instrumento da pesquisa científica, a sua apropriação e uso pelas Ciências Sociais e em especial pela Ciência da Informação. 
Foi por meio do estudo e análise dos registros fotográficos dos objetos da casa do escritor Jorge Amado, que compõem o livro Rua Alagoinhas 33, Rio Vermelho (RUA..., 1999), em especial, aqueles encontrados em sua sala de visitas, que realizamos esse intento, que se reveste do desejo de identificar, nesses registros, as marcas das relações socioculturais que foram tecidas pelo escritor, ao longo do tempo.

Essas imagens se constituem em uma representação dos espaços e objetos da casa do escritor, uma realidade ausente, que nos é dada "por delegação", capturada pelo olhar de um sujeito que sobre essa realidade se posiciona e a enquadra, o fotógrafo.Uma realidade representada e mediada, arbitrariamente, cuja leitura não se exaure nas interpretações e reinterpretações possíveis, por estarem à mercê da produção de sentido de quem as olha ou as lê. Estamos, portanto, diante de um realismo que, segundoAumont (1993, p. 105), é resultante “[...] de um conjunto de regras sociais com vistas a gerir a relação entre a representação e o real de modo satisfatório para a sociedade que formula essas regras."

Partindo da premissa de que toda imagem é uma cena recriada ou reproduzida, uma aparência ou conjunto de aparências destacada do lugar e do tempo em que fez sua primeira aparição, ela incorpora uma forma de ver, feita a princípio para evocar as aparências de algo ausente. No entanto, aos poucos foi se tornando "[...] evidente que uma imagem pode ultrapasar, em duração, aquilo que representa ao mostrar como uma coisa ou alguém havia antes se parecido, e assim por implicação, como o assunto fora antes visto por ou adquirido anteriormente por outras pessoas." (BERGER, 1999, p. 12)

Por meio de filtros do presente, as imagens são lidas e, a posteriori, a elas são agregados novos valores e significados que vão construindo e reconstruindo versões em temporalidades distintas, acabando por alterar, muitas vezes, o curso da história. Como diz Gombrich (1986, p. 135), "[...] a significação de uma imagem permanece grandemente tributária da experiência e do saber da pessoa que a contempla", ou seja, cada sujeito imprime à imagem formas de representação e leitura, resultantes da cultura no qual está inserido e de acordo com a sua visão pessoal de mundo.

Para a leitura a posteriori, análise, descrição e decifração visual das imagens fotográficas dos objetos da sala de visitas do escritor Jorge Amado, representadas no livroRua Alagoinhas 33, Rio Vermelho (RUA..., 1999), seguimos um percurso cujo procedimento inicial constituiu-se da pesquisa bibliográfica e documental. Caracterizada quanto à tipología como uma pesquisa exploratória, ela foi guiada pelo método heurístico, cuja escolha foi inspirada na leitura e decifração da Prancha 79, de Aby Warburg, realizada pelo antropólogo Samain (2012). Nas etapas de desmontagem e remontagem das imagens fotográficas, apelamos para a intuição e a percepção, principios recomendados pelo método, agregando à leitura novos valores e significados, construindo versões e narrativas que nos fizeram atingir o que pretendíamos, ou seja, demonstrar, através da leitura e decifração do discurso visual, a possibilidade de constuir-se um discurso verbal que deixasse à mostra as relações socioculturais construídas pelo escritor Jorge Amado.

\section{A REPRESENTAÇÃO DO REAL}

A representação implica uma coisa no lugar da outra, como Gil (2000, p. 12) a considera na Enciclopédia Einaudi.

Em todas as formas de representação uma coisa se encontra no lugar de outra, representar significa ser o outro dum outro que a representação, num mesmo movimento, convoca e revoca. Reteremos essa significação como uma determinação mínima. $\bigcirc$ representante é um duplo do representado. (GIL, 2000, p. 12).

Não nos limitando à etimologia ou ao conceito para um melhor entendimento sobre imagem e representação, recorremos a teóricos como Aumont (1993), pensador dedicado aos problemas que envolvem o conhecimento contemporâneo sobre o assunto; a Pesavento (2005) e Bachelard (2008), por se reportarem à imaginação como um caminho para se entender a realidade; a VilémFlusser (2011) por nos fazer entender que a imaginação é a capacidade de fazer e decifrar imagens, bem como por considerar as imagens técnicas, e dentre elas a fotografias, tão simbólicas quanto todas as imagens.

Na área da Ciência da Informação, as pesquisadoras Alvarenga (2003), Andrade (2006), 
Manini (2011), Curras (2010) e HildeniseNovo (2013) abordam questões que envolvem a imagem e a representação da informação e do conhecimento no contexto da ciência e da pesquisa. Quanto à posição do leitor/espectador, uma das razões essências da fabricação de imagens, Aumont (1993, p. 78) considera que a representação "[...] provém da vinculação da imagem em geral com o domínio do simbólico, o que faz com que ela esteja em situação de mediação entre espectador e a realidade."

Como um dos valores da imagem em sua relação com o real, a representação é um processo pelo qual se institui um representante que, em certo contexto limitado, tomará o lugar do que representa, apesar de toda arbitrariedade do processo de instituição de um substituto. $\mathrm{O}$ caráter de evidência, nesse sentido, é colocado em xeque, especialmente aquele atribuído à imagem fotográfica que, como uma representação, é assentada em convenções socioculturais.

Não se pode esquecer que, desde sempre, o homem criou e desenvolveu formas de se comunicar buscando estabelecer, com o outro, relações sociais e, sobretudo, dar visibilidade ao pensar e sentir por meio de representações, cujo propósito era repassar o conhecimento que ia adquirindo sobre si e sobre a realidade que o cercava. Vale ressaltar que a impossibilidade do homem de abarcar e entender o mundo, a própria produção de conhecimento, o tem levado à busca de formas de interpretação e representação desse mundo, uma ânsia ontológica pela permanência do ser e das coisas, pelo seu entendimento, que vem de tempos imemoriais. Desde as cavernas, desde Aristóteles que, diante da existência de todos os tipos de entidades abstratas ou concretas, bens, coisas, ente, constituintes da existência do mundo, ele criou categorias que buscavam classificá-las, levando em conta as diferentes propriedades das espécies do mesmo gênero.

Quando Andrade (2006, p.47) analisa as representações no universo do conhecimento, referenda as premissas que apresentamos anteriormente. A autora assim se expressa:

No processo de transmitir informações, - homem foi criando meios de registrar conhecimentos e elaborou o processo de registro e construção do conhecimento por meio de representações. Estas traduziam e traduzem a visão de mundo que cada um de nós possui em determinado momento sócio-cultural e histórico e que está também presente nas linguagens utilizadas e nos suportes disponíveis. [...] o registro do conhecimento por meio de representações revela a relação das ideias e das ideologias com as técnicas. (ANDRADE, 2006, p.47)

Esse processo, no âmbito da Ciência da Informação, visa materializar a informação contida em documentos, nos seus mais variados suportes, convertendo-a numa linguagem que deve estar voltada para o entendimento humano, para a difusão e disseminação da informação. Como preconiza Currás (2010, p. 18), a organização do conhecimento representado é a causa, a origem e a consequência das atividades cognitivas humanas, desde quando a busca pela representação e organização da informação se dá utilizando-se das linguagens disponíveis no contexto da produção e comunicação do conhecimento; e por ser algo eminentemente social, a linguagem é e tem sido organizada em sistemas aceitos e reconhecidos pelas comunidades que dela se utilizam, sendo ela uma representação do real.

Partindo-se do princípio de que toda representação do conhecimento é social e simbólica e que representar significa o ato de colocar algo no lugar de, é que ela consiste na assimilação dos bens, das coisas, dos entes, num processo cognitivo que, na perspectiva de Alvarenga (2003), inclui as etapas de percepção, identificação, interpretação, reflexão e codificação. Ao viver essas etapas é que o sujeito cognitivo vai se apercebendo de um novo ser, de uma nova coisa, vai se aprofundando no conhecimento do já conhecido por meio dos sentidos, da racionalidade, emoção e da linguagem em um processo de conhecimento, na assimilação das coisas por meio de suas representações.

No mesmo diapasão que os autores citados, Novo (2013, p. 116) esclarece que: “A representação é um processo mental pelo qual o indivíduo busca o significado, descrevendo o que deve ser representado e designado, onde a relação sujeito $x$ objeto se estreita para que se possa alcançar a interpretação do mundo a ser representado." Não foge, portanto, à conceituação de que, ao representar a realidade, 
estamos colocando algo em lugar de outro, com o objetivo de materializar a imagem que foi, em sua gênese, produzida pela mente do homem, ou mesmo de algo já existente, em sua fisicalidade.

\section{I Representar o real: como isto sucede com a imagem fotográfica?}

Vejamos! Quando surge a fotografia, antigas formas de representação do mundo foram ameaçadas. Registrar e produzir imagens do mundo, da natureza e dos homens tal como se apresentam, desestabilizou antigas formas de representação. A pintura foi uma delas. A “[...] sua objetividade confere, de forma unânime, um papel determinante como documento desde o seu advento," como afirmam Bucceroni e Pinheiro (2009, p. 2).

Contestada por alguns quanto ao valor de representação, a fotografía foi ao encontro a um meio artístico que não era acostumado a uma forma de reprodução tão mimética e objetiva, que não se apropriava da técnica para a reprodução do real. Na pintura, entre a realidade do mundo e a sua representação, a mão do homem. Nenhum aparelho. A fotografia se interpôs nesse espaço, introduzindo a técnica. Samain (1998, p. 13) quando procura situar o fotográfico na perspectiva de uma visualidade originária, constitutiva do homem, considera que a imagem fotográfica "[...] teve de atravessar, ao longo de milênios, outros meios de comunicação que foram e são ainda a oralidade e a escrita antes de poder constituir-se como fotografia." Para o autor, que não receia afirmar,

[...] ○ fotográfico representa nossa visualidade primeira que, quase que submersa, durante séculos, nas águas da oralidade e da escrita, remontou, muito recentemente á superfície dando-nos a ver o mundo através de uma mediação técnica suplementar: o próprio dispositivo fotográfico e o signo visual que ele proporciona. (SAMAIN, I998, p. 13)

E, ademais, ao situar o fotográfico nessa perspectiva temporal e como visualidade primeira, antes da fotografia, Samain (1998) reconhece que o mundo primeiro é visto pelo homem; só depois ele é nomeado e dele se fala. Anos foram precisos para que o homem viesse a escrever sobre ele. Representá-lo.
No mesmo diapasão, Francastel (1982, p. 3), quando analisa o universo pictórico e da escrita, possibilitado ao homem e à História e como únicos meios representativos do mundo, alerta para a importância das imagens como fonte de informação e para o fato de que "[...] seria infantil pensar que os únicos valores criados pela História sejam os que a escrita consignou." Advoga no seu livro A realidade figurativa, que a função da arte é ir além do domínio das satisfações fáceis e imaginárias e que ela propicia que atividades fundamentais dessa sociedade sejam reveladas através das "[...] condutas gestos - senso - motores e representações." Atentando para a possibilidade de as imagens serem, simplesmente reduzidas ao signo, o que nada significariam, aponta para o fato de que

[...] por seus elementos, a imagem é
exatamente o reflexo da experiência
pessoal na medida em que é comum
a um certo número de indivíduos,
ela é por essência, ao contrário,
elaboraçãocriação de um mundo
não, é claro, como se costuma dizer,
absoluto, mas irreal e deformável a todo
momento, suficientemente imaginário
[...]. (FRANCASTEL, 1982, p. 3)

Novas formas de ver o mundo e o fotográfico coincidem com o momento em que se instaura, segundo Pesavento $(2005$, p. 9), "[...] uma crise de paradigmas explicativos da realidade, [que ocasionou] rupturas epistemológicas profundas que puseram em xeque marcos conceituais dominantes na História." Modelos e regimes de verdade entraram em colapso e a realidade, sua representação e mimetismo, escaparam aos "marcos racionais e da logicidade." Marcos que também são realçados por Dubois (2012), quando narra os modelos correntes de análise sobre a fotografia, apontando para o marxismo e a corrente dos Annales como defensores de matrizes interpretativas da realidade.

Esse é um tempo em que a veracidade dos fatos históricos é também colocada em xeque, assim como a verossimilhança e a veracidade dos discursos. Tempo que, na perspectiva de Pesavento (2005, p. 9), desloca-se a "[...] atenção dos objetos para os métodos de estudo," e contexto no qual Ricouer (1994-1997) lança a obra Tempo e narrativa, considerando que toda narrativa histórica representa um tempo 
passado, na qual o leitor busca encontrar o real. Na perspectiva do autor, toda narrativa se estrutura no sentido de representar e reconstruir esse tempo passado e como uma representação, busca colocar-se no lugar do acontecido, afirmar que "isso foi," estava lá, e dar-lhe um significado, tanto quanto as representações fotográficas.

Vale ressaltar que todo acontecido representado nas imagens fotográficas é fruto de escolhas, nas quais as técnicas interferem, bem como as infinitas possibilidades de enquadramento do real por parte do sujeito. A maneira de se estar no mundo, o ângulo como se olha e se pensa o mundo, a possibilidade de se dizer "isso foi," em cada época e lugar, levam os homens a construir representações, formas de expressão e tradução da realidade que buscam dar sentido ao real, às coisas, às ações, aos sujeitos. Tais formas, carregadas de sentido, se apresentam muitas vezes de maneira cifrada, cheias de significados e valores, o que leva uma corrente de pensadores, e dentre eles Pesavento (2005), a considerarem que o imaginário se tornou um conceito central para a representação e análise da realidade.

Para a autora, o imaginário passa a traduzir a experiência do vivido e do não vivido, das coisas vistas e imaginadas, do suposto, do desconhecido ou desejado, havendo um lado que se reporta à vida e outro que se reporta ao sonho. Em cada época e lugar, os homens constroem representações imagéticas que buscam dar sentido ao real, daí o imaginário que se constrói ser datado, histórico, comportando valores, mitos e ideologias. Partindo desses pressupostos, a imagem é tida como a representação de uma realidade cultural, através da qual o indivíduo ou o grupo que a elabora revela e traduz o espaço cultural e ideológico no qual está inserido, podendo a sua representação ser considerada "sintoma" de uma época e das ideias de homens de outros tempos. A reconstituição das idéias e dos sentidos conferidos ao mundo manifestamse em palavras, discursos, imagens, coisas e práticas,

Como representações codificadas da realidade, as imagens fotográficas são criadas com um determinado fim e uso, seja individual ou coletivo. Como mediadoras entre o homem e o mundo, as imagens se propõem a representar esse mundo, desde quando, de início, este não lhe é acessível. Essa questão nos leva de volta ao discurso de Aumont (1993, p. 80) para quem, na fabricação da imagem, subjaz o desejo de

estabelecer uma relação com o mundo e as coisas que podem ser atestadas através dos modos: simbólico, epistêmico e estético. Para o autor, a realidade é sempre construída por regras determinadas e a imagem, como uma representação, é interpretada de acordo com valores implícitos nos padrões culturais do olhar social.

No entanto, por não estabelecer uma relação determinista com o signo, a imagem, segundo Francastel (1982, p. 107), “[...] é tão variável quanto o número de espectadores [e] não é mais estável do que as interpretações", daí elas não se situarem no objeto representado, mas no espírito dos seus usuários que, em distintas temporalidades,emprestam a elasdistintas versões. Essas premissas também nos levam a reconhecer que, por meio de imagens representativas de determinada cultura, podemos perceber a noção de mundo, bem como os mecanismos sociais que acabam por determinar os padrões de percepção.

A determinação desses padrões é refletida por Flusser (2011) quando analisa, criticamente, a relação que se estabelece entre as imagens e seu receptor.

\begin{abstract}
O homem ao invés de se servir das imagens em função do mundo, passa a viver em função de imagens. Não mais decifra as cenas da imagem como significados do mundo, mas o próprio mundo vai sendo vivenciado como conjunto de cenas. (FLUSSER, 20I I, p. 23)
\end{abstract}

Fica evidente que não podemos abordar questões sobre a imagem técnica, na contemporaneidade, sem levar em conta a sua singularidade, sem transpor a fronteira entre a percepção visual e a percepção cognitiva, sem dela nos aproximarmos através de mecanismos de compreensão de sua produção de sentido. Fica configurado que uma imagem fotográfica não é jamais a re-produção de uma representação anterior, que ela é sempre a proposta de uma representação futura, uma imagem precária como a considera Schaeffer (1996, p. 57).

\subsection{Como documento não foge à regra}

A verdade dos fatos das coisas não coincide com a verossimilhança dos 
discursos e das imagens. Apesar de seu contato com as coisas, a fotografia documento não foge à regra: ela própria obedece à lógica da verossimilhança, não a da verdade, a passagem da verossimilhança para o real e para o verdadeiro é, também com ela sempre sinuosa e improvável. (ROUILLÉ, 2009, p. 76)

O trajeto feito pela fotografia, que a fez passar de uma invenção do século XIX, caracterizada pelos traços puramente documentais de representação da realidade, para a sua utilização como uma ferramenta eficaz de análise da sociedade e da cultura, andou em paralelo com a mudança no conceito de documento que reverberou sobre o valor epistemológico negado e ora agregado à imagem fotográfica como documento na pesquisa e produção científica. Desde o seu advento, a fotografia foi considerada uma ferramenta utilitária, capaz de captar a realidade, o que viabilizava o seu uso prático e a sua inserção na dinâmica da sociedade industrial.

No século XIX, a sociedade buscava uma forma de representação do mundo que atendesse aos seus anseios, à organização social, política, ao nível do crescimento e avanço tecnológico atingido. Foi a fotografia a melhor resposta a esse anseio e necessidade, cuja legitimidade se ancora nas suas funções documentais, pensamento comungado por Bucceroni e Pinheiro (2009, p. 2), quando afirmam que a "[...] sua objetividade confere, de forma unânime, um papel determinante como documento desde o seu advento."

A mecanização da produção da imagem fotográfica, nesse período, trouxe a reboque a racionalização e a aceleração do seu processo de produção, no entanto, não trouxe consigo nenhuma modificação no que tange à representação do homem e do mundo, muito menos o seu acolhimento como uma fonte de informação. Foram as mudanças advindas das transformações ocorridas no final do século XIX e início do século $X X$, a respeito do conceito de documento e sua ampliação, agora visto como instrumento de promoção e circulação social do conhecimento, que determinaram um novo pensar sobre a fotografia e seu valor documental. O debate em relação ao uso da fotografia como elemento para análise da pesquisa histórica foi estabelecido em consonância com alterações ocorridas no âmbito da própria História, da corrente historiográfica da Escola dos Annales.
Esta propunha validar a fotografia não só como documento, mas como um documento-subsídio para os estudos historiográficos, utilizado nas pesquisas sobre a sociedade e suas práticas.

Segundo Le Goff (2003), estudioso dos Annales, a investigação histórica deveria ampliar o leque documental para além dos registros escritos e orais, contexto no qual a fotografia passa a ser compreendida como documento e registro válido para o estudo da disciplina História. Tais alterações passaram a considerar a fotografia como detentora de uma sintaxe própria ao estabelecerem-se novos conceitos de realidade, outras modalidades metodológicas, matrizes teóricas menos rígidas, novas formas de pensar o fazer histórico, referenciais de análise mais atuais, novas formas de olhar o social e suas representações. A repercussão na renovação dos conceitos atribuídos ao documento, em diferentes áreas do conhecimento, se deu de forma visível.

Consciente de que as fotografias são portadoras de pensamento e como tal nos fazem pensar que são registros da cultura material, do comportamento, hábitos e costumes, Samain (2012) alerta para o fato de sermos conduzidos, no mundo ocidental, por uma ordem epistemológica que privilegia o verbal escrito em detrimento da imagem. Somos guiados por uma ordem em que a percepção mágica que dá início a qualquer construção cultural foi confrontada pela lógica da escrita linear, que acabou por impor uma postura mais racional, determinante na relação do homem com o mundo e consigo próprio, no processo de acumulação de conhecimentos e de trocas sociais na qual a supremacia da escrita prevaleceu.

Não só na História, mas em outras Ciências Sociais e Humanas, o conceito de documento sofreu mudanças significativas das quais destacamos aquelas advindas do pensamento de Briet (1951) e Otlet (1996), referências sempre presentes, quando o assunto tratado é a Documentação. Para Otlet (1996, p. 43) a noção de documento "[...] cubre a la vez todos los tipos: volúmenes [livro], folletos, revista, artículos, cartas, diagramas, fotografías, estampas, certificados, estadísticas, incluso discos fotográficos e películas cinematográficas." Os esforços voltados para uma conceituação funcionalista do documento encontraram em Otlet, em 1934, um precursor. Ele propunha que documento como um termo genérico abarcasse não só os documentos escritos, mas aqueles caracterizados como iconográficos e audiovisuais. 
(OTLET, 1996). Na esfera da Documentação, ele antecipa e amplia a noção ao afirmar que os objetos podem ser vistos como documentos, por considerar que livro e documento se constituem como "[...] un suporte de una ciertamateria y dimensión, [...] enel que se inclyem signos representativos de ciertos dados intelectuales". (OTLET, 1996, p. 43)

Quando Bucceroni e Pinheiro (2009, p. 10) discorrem sobre o Zoom de Otlet na fotografia, no artigo sobre a A imagem fotográfica como documento: desideratos de Otlet, afirmam que "[...] a fotografia é para Otlet, o tipo de documento gráfico que melhor exprime o conhecimento humano, por ser o mais realista." A visível crença na objetividade que grassava nesse período, o estigma do mimetismo atribuído à fotografia, consubstanciaram a crença de Otlet (1996, p. 200) na fotografia como mímese do real, levando-o a afirmar que "La fotografia es el medio de representación más realista, aquel cuya objetividad mecânica alcanzala más preciada aproximación cuando se trata de obtner de La naturaleza um imagenen dos dimensiones."

Um pouco mais a frente, na França, Briet (1951, p. 7), no artigo Qu'est-ce que ladocumentation?, retoma a discussão sobre a noção de documento e documentação, propondo uma releitura dos conceitos de Otlet e da L' Union Françaisedes Organismes de Documentation. Constata que o documento é "[...] toda base de conhecimento fixo materialmente e susceptível de ser utilizado para consulta, estudo ou pesquisa." ${ }^{1}$ A autora propõe outra definição que julga mais atual e abstrata, ou seja. que o documento é "[...] todo signo indicial concreto ou simbólico, preservado ou registrado para fins de representação, de reconstituição ou de prova de um fenômeno físico ou intelectual." ${ }^{2}$ (BRIET, 1951, p. 7, tradução nossa)

A noção de documento como signo, uma proposta de Briet (1951) para quem o documento se configura como uma evidência física, leva-nos a crer que todo documento é um signo indicial e que arroladas estarão as fotografias na sua conceituação de documento. Para a autora, a fotografia como documento passa a ser um signo por ser o resultado de uma apreensão do real que leva à comprovação de um fato ocorrido, cuja perspec-

\footnotetext{
I "[...] toute base de connaissancefixéematériellementetsusceptible d'êtreutiliséepourconsultation, êtude ou preuve."

2 "[...] touteindiceconcret ou symboliqueconservé ou enregistré, aux fins de représenter, de reconstituer ou de prouver unphénomène ou physique ou intellectuel."
}

tiva é viabilizada pela técnica. Como observou Buckland (1997), a materialidade do documento para Briet (1951), a intencionalidade do sujeito e a forma como é processado são os critérios que devem ser usados para defini-lo. Tendo partido em defesa de pressupostos que consideram a informação como coisa, a informação como processo e a informação como conhecimento, Buckland (1991) prioriza a materialidade como um fator fundamental para o fazer documentário, tal qual Briet, e na sua perspectiva a informação como processo e a informação como conhecimento são intangíveis e a informação como coisa se reporta à materialidade da informação.

Vamos encontrar em Manini (2012), partindo das proposições de Buckland, (1991) uma abordagem semelhante aplicada ao documento fotográfico, quando ela faz uma leitura da tríplice concepção do autor: a fotografia como informação como coisa, que remete a objetos fotográficos (negativos de vidro e flexíveis, positivos em papel, diapositivos); a fotografia como informação como processo, que remete à pesquisa histórica contextualizadora da imagem e sua correlação com outros documentos fotográficos ou textuais ou outros quaisquer na construção e/ou amplificação de sentido da imagem; e a fotografia como informação como conhecimento, que remete a resultados de investigações e pesquisas de caráter comparativo entre fotografias e textos históricos.

Outras formas de entendimento e uso da fotografia como documento e como um meio de observar e fixar o efêmero, pelo qual podemos acompanhar as transformações sociais, comportamentos e a desaparição do mundo, estão associadas a disciplinas nas quais a fotografia tem sido utilizada largamente, conforme declaração da pesquisadora Tardy (2015, p. 251):

Esta capacidade de tornar visível uma extensão espacial através da ferramenta fotográfica nas ciências humanas concerne mais amplamente às ciências da astronomia, da biologia, da medicina, da arqueologia, que têm uma longa tradição na forma de equipar o olho para fazer emergir o invisível ou o não perceptível. ${ }^{3}$ (tradução nossa)

\footnotetext{
3 Cette capacité à donner à voir une étenduespatiale par l'outilphotographiquedans les scienceshumainesrejoint plus largement les sciencies de l'astronomie, de la biologie, de la medicine, de l'archéologie, quiont une longuetraditiondans la maniéred'equiperl'oeilpour faire remonterl'invisibleou le non-perceptible.
} 
As ciências sociais vêm incorporando a fotografia nas suas pesquisas e na prospecção de dados, opção que não era acatada há décadas. Nos dias de hoje, há um reconhecimento da imagem fotográfica como documento produtor de sentido, cuja busca do significado está sujeita ao encontro com a sua referencialidade e seu caráter polissêmico que convida à interpretação, porta aberta à subjetividade. $\mathrm{O}$ desafio que se apresenta a quem se propõe a considerar a fotografia como documento é a tensão que se estabelece entre o olhar referencial e a subjetividade, tão bem explicitada por Sontag (1981, p. 220), quando chama a atenção para o fato de que "A fotografia, na verdade é incapaz de explicar o que quer que seja, é um convite inexaurível à dedução, à especulação e à fantasia."

Ao promover a circulação social do conhecimento e por ter reconhecida a sua potencialidade informativa e mediadora, a fotografia tem recebido um tratamento documentário especial. O estatuto que a ela vem sendo outorgado, como documento, tem repercutido na adoção de novos olhares e métodos para sua análise e interpretação que, na contemporaneidade, têm sido adotados por parte das Ciências Sociais e em particular pela Ciência da Informação, como tentamos demonstrar.

\section{O QUE DIZEM AS IMAGENS FOTOGRÁFICAS: UM PERCURSO METODOLÓGICO PELA SALA DE VISITAS}

Configurou-se como o objetivo deste estudo, averiguar e demonstrar, por meio de análise e leitura dos registros fotográficos como representação de objetos que compõem uma casa, basicamente a sala de visitas, se eles podem se constituir numa fonte de informações sobre o capital social e cultural de um sujeito, no nosso caso, do escritor Jorge Amado, como já explicitamos. Para um melhor entendimento sobre os usos sociais da técnica fotográfica, a perspectiva de Bourdieu e colaboradores (2003) e Bourdieu (2008), contida nas obras Unartmoyen: essaissurlesusagessocieaux de laphotographiee A distinção: crítica social do julgamento, nos fez entendê-los, assim como considerar a predisposição ao gosto pela arte como um marcador social e seus diferentes modos de aquisição.

O método heurístico foi o escolhido para esta pesquisa por caracterizar-se como intuitivo e experimental e por utilizar-se da criatividade, da intuição, da percepção e da erudição para análise do objeto: as imagens fotográficas dos objetos da sala de visitas do escritor, registrados no livro Rua Alagoinhas 33, Rio Vermelho (RUA..., 1999). Adotamos a pesquisa bibliográfica e documental como procedimentos que, pela singularidade e caráter multidisciplinar, abarcou literaturas nacionais e estrangeiras oriundas das áreas da Antropologia, da História, da Sociologia, da Filosofia, da Ciência da Informação e afins.

A pesquisa documental constituiu-se da escolha da foto da sala, da identificação de cada figura/objeto, da elaboração de uma ficha técnica com categorias identificadoras: autoria, data, local e tipologia, à qual foi acrescido um resumo temático, contendo informações que enriqueceram o estudo. Sistematizadas, essas fichas técnicas perfizeram um total de 52, mas apenas 32 delas foram analisadas, por trazerem as assinaturas de seus autores, informação que sinalizava para as relações com artistas e artesãos construídas pelo escritor.

\section{I As etapas da tríplice operação heurística}

A proposta metodológica para a leitura, categorização e análise das fotografias foi inspirada na desmontagem e remontagem de uma prancha do Atlas Mnemosyne, da Biblioteca MnemosynedeAbyWarburb, a Prancha 79. Sobre esta obra, Didi-Huberman (2013, p. 383) afirma que "[...] Antes de mais nada Mnemosyne é uma disposição fotográfica [que] forma um quadro sobretudo no sentido combinatório - uma 'serie de séries', pois cria conjuntos de imagens, os quais em seguida relaciona entre si."

Considerada um sistema complexo de imagens, a prancha 79 foi desmontada e remontada pelos editores da obra e usada como objeto de estudo por Samain (2012), 
antropólogo e pesquisador da UNICAMP, cujo modelo adotado aqui apresentamos. A sua tríplice operação:1) Identificação- consiste em nomear a temática central de cada figura/ objeto representada nos registros fotográficos, através da análise e decifração de dados tais como: tipo, autoria (artista/artesão); local, data, dados técnicos; 2) Numeração e ordenação das figuras/objetos - consistem na interpretação, por meio de uma possível ordem numérica, de um sistema de numeração das figuras que obedece aos parâmetros: agrupamento por temática, vizinhanças, associações, parentescos, aproximações, às vezes, pelas diferenças; 3) Resumo temático- consta de palavras-chave representativas da sala como um todo. A definição e composição das temáticas é a etapa que caminha para a remontagem da sala de visitas.

Na etapa da desmontagem, constitutiva da identificação, numeração e análise dos resumos temáticos de cada figura/objeto representado, foram aflorando as palavraschave que vieram a compor as temáticas adotadas: Objetos diversos; Figuras da cultura baiana e brasileira; Animais; Candomblé; Flores e frutos; Marinha; Catolicismo; Mobiliário, uma composição articulada pelas afinidades, semelhanças e analogias, que abriu caminho para a remontagem da sala de visitas da casa da Rua Alagoinhas 33.

De cada objeto analisado e descrito, buscamos identificar o modo de aquisição, o tempo, a origen, momento em que o discurso visual possibilitou que um discurso verbal fosse construído.Cada relação estabelecida entre o escritor e o artista foi pesquisada com a finalidade de encontrar-se o sentido da existência do objeto ali representado, o valor a ele agregado e de se obter indícios das crenças, valores, afetos, senso estético, trajetórias, afinidades, que pudessem apontar para a rede sociocultural tecida pelo escritor Jorge Amado.

Como parâmetros e seguindo a proposta do método, esses indícios nos conduziram a avaliar e perceber, ou mesmo a intuir o nível e o aprofundamento da relação mantida entre artistas, artesãos e o escritor, baseados nas afinidades refletidas nas escolhas e nas apropriações, levando em consideração a sincronia temporal estabelecida entre o escritor, os artistas e as obras. No entanto, das imagens fotográficas analisadas, como imagens "sobreviventes," aparições, ressurreições foram surgindo da superficie e ao serem removidas as camadas de informações sobrepostas sobre elas, acumuladas pelo tempo, vozes e silêncios passaram a ser ouvidos.

Para proceder à remontagem da sala, apelamos para o conhecimento tácito de que dispúnhamos; para acriatividade, intuição, percepção e erudição propostas pelo método; para os fundamentos que construíram a base teórica, aliados aos dados levantados e às declarações que colhemos do fotógrafo e de familiares. Pela análise das temáticas instituídas, demonstramos como foram puxados os fios históricos e memoriais que permitiram reconstituir uma história e tecer uma rede sociocultural do escritor, mediante a mediação das imagens fotográficas da sala de visitas, registradas no livro Rua Alagoinhas 33, Rio Vermelho. (RUA..., 1999).

Alicerçadas essas distintas relações, na cultura baiana e brasileira, no sincretismo religioso que professava, nas afinidades e vivências literárias e políticas, nos afetos, elas podem muito bem ser entendidas pelo discurso de Bourdieu (2008, p. 135) quando chama a atenção para a existência de estratégias de distinção que advêm tanto do produtor da obra, quanto do consumidor, estratégias que fazem com que "[...] o encontro com a obra seja freqüentemente vivido na lógica do milagre e da paixão súbita. E que a experiência do amor à arte se exprima e se viva na linguagem do amor."

Dentre as temáticas analisadas elegemos, como exemplo, a Temática 2 - Figuras da Cultura Baiana e Brasileira, composta por imagens fotográficas nas quais fica visível, e não há que se fazer esforço para perceber, a faceta do perfil eclético e catalisador do escritor, exposta na convivência harmoniosa entre o erudito e o popular, na diversidade dos estilos e das origens dos objetos que compõem o seu museu imaginário. $\mathrm{Na}$ riqueza e variedade das relações que foram construídas. A sua distinção. 
Figura: Temática 2 - Figuras da Cultura Baiana e Brasileira
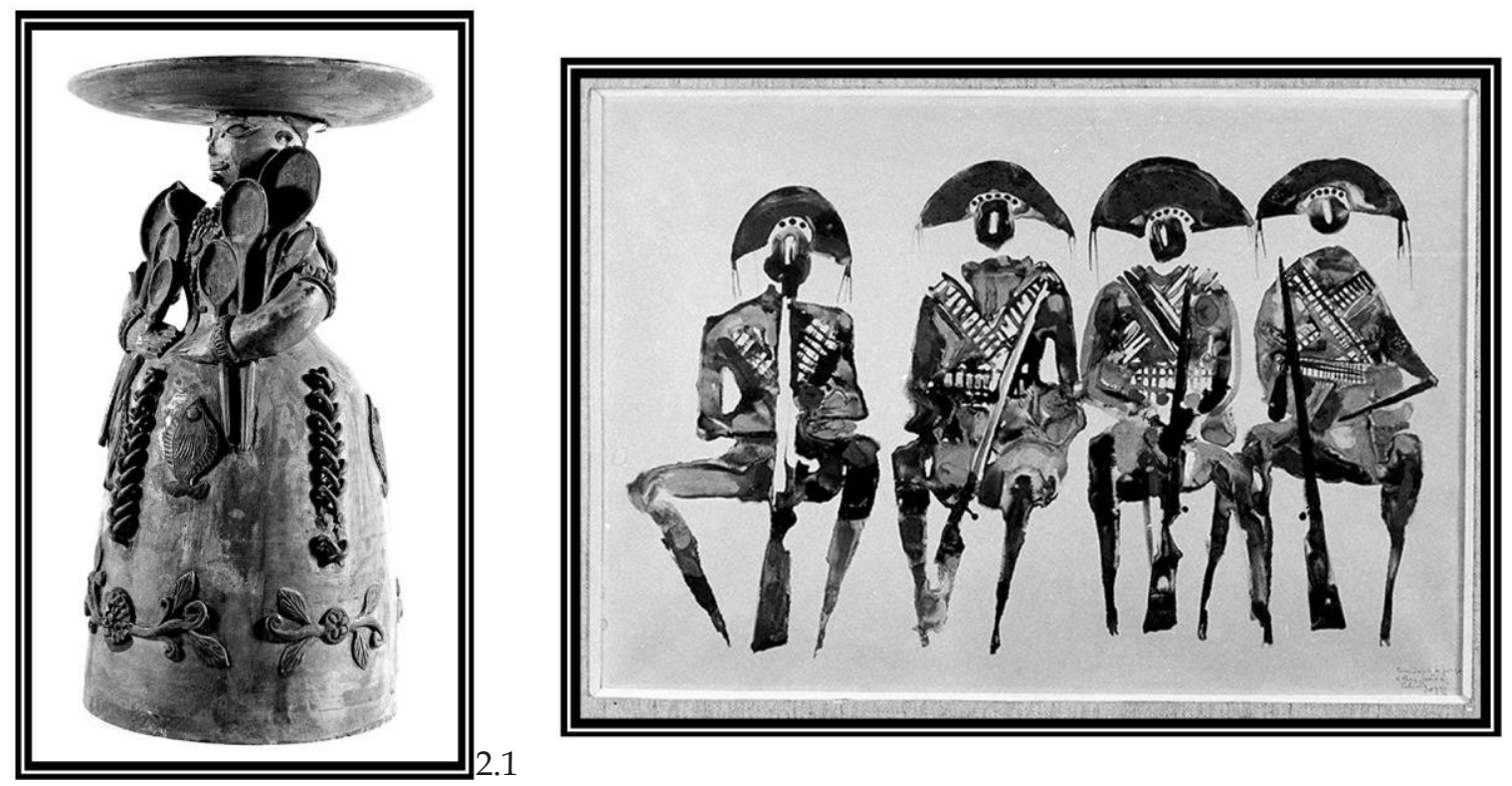

2.2
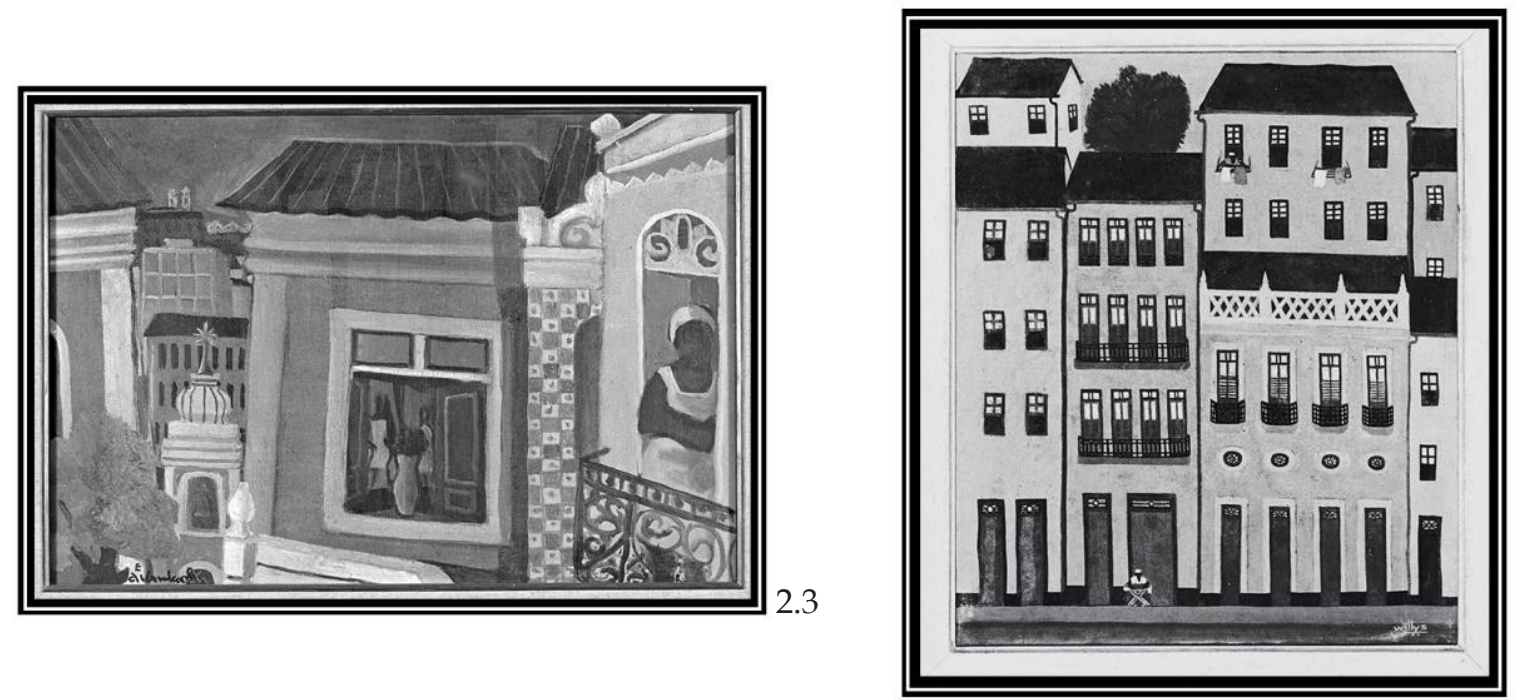

2.4

Fonte: Fotos de Adenor Gondim

Os registros fotográficos de número 2.1, 2.2, 2.3 e 2.4 compõem um conjunto temático de figuras/objetos que representam elementos da cultura baiana e brasileira, presentes nas obras de Carybé, Di Cavalcanti e Willys. É como se os olhares desses artistas se voltassem para a mesma direção do olhar do escritor Jorge Amado. Para a Baiana, figura/objeto 2.1, e os Cangaceiros,
2.2, de Carybé, para a Paisagem com moça na janela 2.3, pintada por Di Cavalcanti, e para os Sobrados, 2.4, de Willys, obras que representam tipos e cenários que povoam o imaginário de artistas e escritores, que encenam pessoas, moradas e as ladeiras não só da Bahia, mas de dezenas, centenas de cidades desse país. Mulheres, homens e cenários que compõem as 
páginas dos inumeráveis romances de Jorge Amado, cujas visões imaginárias, construídas por brasileiros e estrangeiros, sobre a Bahia e o Brasil, são alimentadas pela vida e obra do escritor.

Executadas na década de 1960, entre os anos de 1960 (2.3), 1962 (2.2) e 1968 (2.4), , essas obras estão inseridas num tempo de ebulição e dinamismo cultural em que "[...] o país vive um processo de modernização técnica e de renovação cultual manifestada pelo surgimento de diversos movimentos artísticos que atingiram profundamente a sociedade brasileira". (CARVALHO, 1992, p. 47). Anos efervescentes no plano da cultura, anos da contracultura, da recuperação do exótico, do diferente, da valorização do outro, de povos distantes, orientais, da cultura negra e indígena. É o tempo do Brasil de Juscelino Kubitscheck, da chegada da televisão, da Bossa Nova, do Teatro de Arena, do Instituto Superior de Estudos Brasileiros (ISEB), que inspiram um clima de euforia desenvolvimentista no Brasil e amplas transformações sociais.

A Bahia de Magalhães (1959-63), também respirava os ares de modernização, movida pelos ecos do discurso modernizador do governo Kubitschek. Na Universidade, os reflexos se fazem sentir nas transformações vividas sob a égide do Reitor Edgar Santos que a insere nesse processo, por meio da implementação de ações renovadoras que favorecem uma ambientação propicia à geração de artistas e intelectuais.

Muitos deles, Jorge Amado, Carybé, Mário Cravo, Willys, Calasans Neto e tantos outros, ao verem sua terra buscando a afirmação da identidade, imprimem às manifestações culturais fortes características de "baianidade". (SÁ, 2010) A busca pelas raízes, pela origem, pela identidade, aflora na classe média e na intelectualidade, cujo anseio era o de representar a cultura de sua terra e de seu povo através do exotismo e da exuberância, da sua diferença. Por meio das expressões culturais que lhes eram próprias. Um projeto nacional de recuperação das origens que remetem à Bahia, desde quando "Os artistas plásticos afro-baianos ou seus simpatizantes arregimentaram-se para dar visibilidade aos impulsos criadores [...]" conforme declaração do pesquisador Veiga (2006, p. 112).

São desses anos as músicas cantadas por Elis Regina - Arrastão, de Ruy Guerra e Edu Lobo,
Canto de Ossanha, de Vinícius de Moraes e Baden Powell, tempos do cinema Novo, do Pagador de promessas, da literatura de Jorge Amado, das artes de Carybé, de Mário Cravo e tantos outros. Na perspectiva de Prandi (2009), esses são anos de produção de uma nova forma de cantar, em que elementos do candomblé vão se firmando, em que as mães de santo vão sendo reverenciadas por artistas e intelectuais, tais como Olga de Alaketo e Mãe Menininha do Gantois. Vale ressaltar que foi no início dos anos de 1960 que Jorge Amado e Carybé foram agraciados com o mais alto título do candomblé, o de Obá Orolu, pelo Axé Opô Afonjá, de Mãe Stela de Oxossi, o que veio a reforçar a presença das mitologias do candomblé na produção de suas obras.

Nesse contexto, propício à criação de afinidades e aproximações, Jorge Amado transitava e mantinha com pintores/artistas e artesãos uma relação que ultrapassava o plano da amizade, a qual era ungida por afetos, identidades, especialmente com Carybé, por uma religiosidade professada nos terreiros de candomblé. Muitas páginas por ele foram escritas louvando a relação que mantinha com artistas e artesãos das artes da Bahia. Não se furtava o escritor a tecer elogios, a cobrir as paredes da casa com suas obras, muitas vezes inspiradas nos personagens de seus romances, obras que se alojavam, muitas delas, na sua sala de visitas. Tanto é que um painel de Calasans Neto, formado pelas talhas originais que compunham as ilustrações do romance Tereza $B a$ tista Cansada de Guerra, cobre uma das paredes do quarto de hóspedes.

Confessa Gattai $(2004$, p. 44) que muito “Teria o que falar dos quadros que embelezam nossa casa, iluminando suas paredes, trazendo ao nosso convívio artistas ainda vivos e outros que já se foram. Lá estão Caribé, Di Cavalcanti, [...] Calasans Neto, Willis, Djanira, Lev Smarcevisky [...]", sujeitos que, privando da intimidade da casa, participaram como artífices, colaborando com a sua construção. Gattai (2004, p. 19) volta a reconhecer os préstimos dos amigos ao declarar que:

Entusiasmados com a vinda de Jorge para Salvador, amigos, artistas e não artistas, alguns deles residentes no próprio Rio Vermelho, ofereceram seus préstimos. Colaboraram para transformar o que era feio em bonito, num recanto aprazível que prenderia o amigo para sempre na terra. 
E o próprio Jorge Amado (1992, p. 68) ao referir-se à participação e entrega dos amigos na construção e embelezamento da casa, afirma, no livro Navegação de cabotagem, que precisaria "[...] vender à empresa ianque os direitos autorais de cinema de outro livro se devesse pagar as doações, as dádivas." E, como diz Amado, foi para prender o amigo para sempre que Carybé tomou de instrumentos, a goiva, o formão, o macete; dos materiais mais nobres, a madeira, o cimento, o barro; e, armado com a força dos orixás, fixou para sempre a face verdadeira da Bahia em tantas pranchas e telas, superfícies e, dentre elas, na casa do Rio de Vermelho, 33, que dessa terra representava uma porção. Foi aquele que, descrito por Gattai (1999), depois de ter nascido na Argentina, aportou aqui na Bahia, com malas e bagagens, para comprovar que tudo o que Jorge Amado tinha escrito em Jubiabá era pura verdade.

Pintor, desenhista, escultor, muralista, escritor e jornalista, integrou-se à Bahia, à sua cultura e tradição, professou o candomblé, dançou capoeira, tocou berimbau, misturouse à terra e ao povo, miscigenou-se. Para Jorge Amado, Carybé foi o mais baiano de todos os baianos, aquele que

\section{[...] plantou raízes fundas na terra baiana como nenhum cidadão aqui nascido e amamentado. Bebeu avidamente essa verdade e esse mistério, fez da Bahia carne de sua carne, sangue de seu sangue, porque a recriou a cada dia com maior conhecimento e amor incomparável. (AMADO, apud BARRETO; FREITAS, 2009, p. I3)}

A amizade que os unia era estreitada pelos laços do candomblé. Eram filhos de Oxossi e Oxum, Obás de Xangô. Uma amizade reverenciada em eventos, palestras, exposições dedicadas a aclamar a relação fraterna que entre eles existia ${ }^{4}$,expressa também em livros produzidos pelo escritor, onde encontramos nas suas páginas e capas, ilustrações e desenhos

4 A exposição "100×100 Carybé llustra Jorge Amado" foi uma realização do Instituto Carybé com a apoio da Fundação Casa de Jorge Amado através da Lei Rouanet. Os objetivos da exposição, nascida em meio à comemoração do centenário de ambos os artistas, são os de promover uma reflexão sobre a importância da relação entre Carybé e Jorge Amado, e tornar este legado mais acessivel à população. A exposição teve a curadoria de Solange Bernabó, filha de Carybé, que no dia 27 de junho, às 17h, na Academia de Letras de llhéus fará uma palestra sobre "Carybé e Jorge, uma amizadecentenária. executados pelo artista. ${ }^{5}$ Amizade declarada nas palavras do escritor, cuja força e a crença na vida e obra do artista são projetadas para um futuro apocalíptico, para o qual ele é alçado a redentor. Assim acredita Amado:

Quando nada mais restar de autêntico, quando tudo se fizer apenas representação, mercadoria e transformar-se em dinheiro na sociedade de consumo, a memória perdurará pura, pois o filho de Oxóssi e de Oxum, o obá de Xangô, guardou a verdade íntegra na criação de uma obra sem igual pela autenticidade, pela beleza, feita com as mãos, o talento e o coração." (AMADO, 2012, p. 177 )

Marcado pela presença de Carybé, pelas figuras/objetos 2.1 Baiana e 2.2 Cangaceiros, o grupo temático Figuras da cultura baiana e brasileira longe está de representar a intensa relação que unia o escritor ao artista. Cantada em prosa e verso, a sua presença ultrapassa a geografia da sala de visita e pode ser medida, ao alojar-se além dos seus muros e paredes. Aloja-se com vigor e exuberância em outros espaços da casa da Rua Alagoinhas, 33, e comparece em todos os seus ambientes, desde a porta de entrada aos lugares mais íntimos.

Peças de sua autoria estão pela casa espalhadas, tais como azulejos que recobrem escadas, orixás, frutas, bichos, peixes, portas, figuras do candomblé, janelas, vigas que, em forma de pássaro, sustentam os telhados da casa. Suas obras estão presentes nas varandas, na piscina, nos quartos, na entrada da casa, no bar, nos fundos. Em bronze, terracota, cimento, tinta, madeira, como lembra Gattai (2004, p. 4950) quando descreve sobre os elementos que comporiam a entrada da casa. "[...] Caribé não perdeu tempo, desenhou um portão de ferro, largo, que em seguida foi feito e colocado: uma beleza! [...] O pórtico de entrada foi, então, revestido de azulejos com desenhos de Caribé."

\footnotetext{
$5 \quad A B C$ de Castro Alves - Capa, O amor do soldado - Capa, Bahia de Todos os Santos - Capa, Capitães da Areia; Capa, O compadre de Ogum - Capa e ilustrações, Dona Flor e seus dois maridos - Capa, Gabriela, cravo e canela - Capa, O Gato Malhado e a Andorinha Sinhá - Capa e ilustrações (todas as edições), Jubiabá- Capa e ilustrações (Edições: 23, 28, 52, $53,54 /$ sendo que as demais edições que possuímos no acervo, Carybé é autor apenas das ilustrações), Mar morto - Capa. Os pastores da noite Capa, São Jorge dos Ilhéus - Capa, Seara vermelha - Capa, Os subterrâneos da liberdade - Capa, O sumiço da santa - Capa e ilustrações, Tenda dos Milagres - Capa, Terras do sem fim - Capa, Os velhos marinheiros - Capa. Fonte: Casa Fundação Jorge Amado
} 
Na sala de visitas fica a figura/objeto 2.1, Baiana, em cerâmica que, em relevo, realça as vestes, os adereços e os instrumentos de trabalho - o tabuleiro -, características identitárias da mulher negra da Bahia, herdadas dos ancestrais, um símbolo da cultura baiana. Nesta sala também fica a figura/objeto 2.2, os Cangaceiros, pintura a guache que representa sujeitos participantes de um fenômeno social do Nordeste, no qual a Bahia está incluída - o cangaço. Esse tema tem ocupado e alimentado o imaginário de escritores, artistas e poetas, ao qual não se furtou Carybé, que chegou a ser, nos anos de 1950, diretor artístico do filme O cangaceiro, de LimaBarreto.

Com um traçado leve, característico do artista, os quatro cangaceiros são representados vestidos a caráter, com chapéu e indumentária de couro, empunhando armas, as espingardas, cartucheiras cruzadas no peito e míticos chapéus que remontam à saga de Lampião. Amado (1999, p.24) os tem em boa conta. Quando se refere a esse quadro do artista, ressalta que "...] pela porta de madeira vazada que entramos na sala, os Cangaceiros de Caribé montam guarda [...]." Como prova da doação, há uma dedicatória: "Para Jorge e Zélia e para João e Paloma", uma inscrição singela que longe está de representar a visceral relação que o unia à família Amado.

Paisagem com moça na janela, figura/ objeto 2.3, representa uma mulata, tendo ao fundo, sobrados e igrejas que sobem ladeiras de uma cidade imaginária. Salvador ou São Paulo? Mulatas e não negras povoam as telas de Di Cavalcanti, tais quais as mulatas nas páginas dos romances amadianos. Nos anos de 1950 e 60, a busca por uma identidade baiana e brasileira vai confluindo para a imagem de uma mulher híbrida, não uma mulher negra, para um modelo, um tipo ideal de mulher, símbolo de identidade nacional. Vai deslizando para a imagem de uma mestiça, para Gabriela, por exemplo, com cor de cravo e sabor de canela, cuja reincidência se configura, posteriormente, tanto em personagens de romances amadianos, como Dona Flor, Tereza Batista, Tieta do Agreste, quanto nas telas do artista.

Como Amado, os temas que Di Cavalcanti aborda são tipicamente brasileiros e em suas telas os temas sociais, como festas populares, figuras do povo, movimentos sociais são representados, refletindo a posição política que ambos assumiam. Por serem membros do
Partido Comunista Brasileiro, primavam por temas inspirados na cultura popular (RUBIM 1995, p. 221). Em sintonia, a sensualidade da mulher mulata é enfatizada nos matizes das cores tropicais que colorem as telas do pintor e no desejo de Amado (1992) de representá-la, como o fez, ao criar suas mulheres mulatas, personagens.

Privando da intimidade do escritor, Di Cavalcanti visita, muitas vezes, a Casa do Rio Vermelho, cultivando uma amizade iniciada nos tempos em que o escritor morava em São Paulo. Foi nesse tempo que o quadro Paisagem com moça na janela, figura/objeto 2.3 chega às mãos do escritor, cuja trajetória é narrada por Gattai (2004) no livro Memorial do amor. Diz-nos a autora que, no tempo em que Jorge Amado morava em São Paulo, um dos quadros de Di Cavalcanti o impressionava pela beleza e do qual muito gostava - Mulata deitada no divã.

\begin{abstract}
Diante do entusiasmo do amigo pelo quadro, generoso, $\mathrm{Di}$ Cavalcanti the disse: 'É teu.' Jorge adotara uma teoria, repetida sempre por um jornalista seu amigo: 'Ao te oferecerem uma obra de arte, não faça cerimônia, aceite sem discutir'. Foi o que ele fez. A Mulata deitada no divã embelezava a sala do apartamento em São Paulo, quando certo dia, Di todo afobado: Vim buscar o quadro. Apareceu um cliente querendo um trabalho meu e eu não tenho nenhum pra remédio. Levo este e pinto outro pra você. (GATTAI, 2004, p.47)
\end{abstract}

Cumprida a promessa, esse outro, Paisagem com moça na janela, figura/objeto 2.3, passou a fazer parte da coleção amadiana no qual, uma dedicatória amorosa, demonstra o afeto que os unia: "Jorge Amado, Zélia Amada, um do outro e os dois meus, o Rio de Jorge, Bahia de Zélia Amada, que também são terras minhas, graças aos dois, graças a Deus, Di Cavalcanti." Essa tela se junta a outras obras do pintor que embelezam as paredes da casa, tais como Gabriela, um guache sobre papel, que foi o primeiro estudo para capa da primeira edição brasileira do romance (1959), e outra Gabriela, óleo sobre tela, com assinatura do artista e datada do ano de 1972. Telas que ficam no Bar e no Quarto do Casal.

Os sobrados e as ladeiras são elementos reincidentes na pintura de Willys, na figura/ objeto 2.4, Sobrados. A força das cores que 
lhes caracterizam são as mesmas encontradas na obra literária de Jorge Amado que os expõe, tanto como espaço representativo do fausto, da herança arquitetônica portuguesa, quanto reduto das desigualdades sociais. A presença marcante dos sobrados na obra do escritor, como cenário revelador de relações sociais, é representada no livro Suor, no qual o número 68, da Ladeira do Pelourinho, transmuta-se em sobrado/ personagem. Justifica-se, portanto, que a tela Sobrados, 2.4 ocupe, na sala de visitas, um lugar de destaque e que ela traga a assinatura e uma dedicatória do artista: "Para Amado, 1968."

Para que se perceba o afeto e a apreciação pela obra de Willys nutrida pelo escritor, bem como as afinidades que os aproximava, torna-se válida a transcrição de alguns excertos que sobre ele foram escritos no livro de autoria de Jorge Amado, Bahia de Todos os Santos: guia de ruas e mistérios. A começar pelo título que os identifica: Willis envolto nas cores da Bahia.

\begin{abstract}
$\mathrm{Na}$ manhã domingueira o pintor Willis desce a Ladeira do Papagaio envolto nas cores da Bahia, vai distribuindo-as em seu caminho, valerão para a semana toda. [...] Casas de esperança verde, românticas cor de rosa, azuis- celeste, corações, violentos azuis marinhos de noivos em ânsia, o amarelo do ciúme e o vermelho da paixão, de todas as paixões. Quem sabe as cores da cidade e de seu lugar exato é o pintor Willis e mais ninguém. (AMADO, 1986, p. 282)
\end{abstract}

O primitivismo da obra do artista e a profusão das cores que utiliza nos seus quadros iluminam a intimidade do escritor e ocupam espaços nas paredes da casa da Rua Alagoinhas, 33, tanto é que no Quarto está exposta a tela Atelier de Alfredo Santeiro, cujo momento da doação representa o nível do afeto e consideração do artista pelo escritor. A declaração de Amado (1999, p.68) comprova o acontecido: "Willys tirou o quadro Atelier de Alfredo Santeiro, de sua parede, para dar a Jorge, pouco antes de morrer."

De Willys repousa na parede da Varanda Fechada o quadro Os Vendedores, tela datada de 1968, e a tela Casario, que pode ser apreciada no ambiente do Bar. Como seu admirador e amigo, Amado (1986, p. 282) propaga a quatro ventos que na Bahia: "Quem sabe das cores do mar, cada um em sua hora exata é o pintor Willis e mais ninguém."

\section{ALGUMAS CONSIDERAÇÕES FINAIS}

Da experiência vivenciada, da adoção e aplicação do método escolhido, ficou ressaltada a riqueza de possibilidades de leitura dada pelos registros fotográficos dos objetos da sala de visitas da casa do escritor Jorge Amado. Como médiuns, as imagens fotográficas não se configuraram como a coisa em si. Delas foi aflorando o seu potencial como representação e documento, fonte de informação, bem como a riqueza de sentidos que podem advir sob o olhar de um receptor. Além da técnica, nos foi permitido observar a sua apropriação e uso social, a função como instrumento de integração do grupo, seja ele familiar ou social, sua dimensão pragmática e seu simbolismo.

Quanto aos objetos, esses se configuraram como veículos de qualificação social, como documentos da memória, suportes de informação que cruzam conceitos espaço-temporais e que, representados nas imagens fotográficas, abriram-nos a possibilidade de entendê-los como produto de uma representação social, resultante do compartilhamento objetivo e intersubjetivo estabelecido entre o sujeito/fotógrafo e a realidade representada, entre os objetos da casa da Rua Alagoinhas, 33, e a nossa forma de ver, pensar e interferir nessa realidade. Como elementos discursivos, representativos da história e da memória, inseridos na cultura do escritor e do seu contexto, deram margem à construção de narrativas através da sua leitura e decifração.

Narrativas, portanto, foram criadas mediante um processo de desmontagem visual e de uma montagem verbal das imagens fotográficas dos objetos da sala de visitas da casa do escritor, momento em que buscamos dar a ver, como nos aconselhou Benjamin (2004), o que não estava à vista, na superfície das imagens, as relações socioculturais por ele construídas.

Ao final dessa caminhada, na qual buscamos dar uma nova ordem, construir um discurso verbal e tecer com outros fios a história das relações sociais e culturais do Jorge Amado, através do caminho metodológico que escolhemos e seguimos, esperamos ter contribuído para que novas apropriações dos estudos sobre a representação fotográfica e especialmente a representação fotográfica de objetos sejam incorporadas e que espaços sejam abertos para outras incursões no campo das Ciências Sociais e em especial na Ciência da Informação. 
Artigo recebido em I3/0I/20I7 e aceito para publicação em 05/02/20I8

\section{THE PHOTOGRAPHIC IMAGE AS A REPRESENTATION AND DOCUMENT: a study from the photographs of objects of the room of visitors of the writer Jorge Amado}

ABSTRACT This study concentrates the question of image as representation and document, its genesis, manufacture, supports and uses, as a construction of man to give meaning to the real. It elects as object, photographic images of the house of the writer Jorge Amado, basically of its living room, as representations that can point to the social and cultural relations built by the writer. The notion of document as a theoretical contribution relates to the concept of Briet (195I), to the thinking of Buckland (I99I), Otlet (1996), Manini (201I) as historical references to a new thinking about its materiality. It reflects on the image as representation, its modes of production, uses and reception. It seeks to identify the path that made photography from a nineteenth-century invention, with purely aesthetic features of reality representation, to an instrument of promotion and social circulation of knowledge, a useful and effective tool for academic research. The research is characterized as exploratory, appropriates the heuristic method, intuitive and experimental, uses a questionnaire as a research instrument and adopts the direct observation of the object. As a result, through reading, classifying description and analysis and a process of disassembly and reassembly, points to the potentiality of the photographic image as a documentary source representative of the sociocultural relations established by the lecturer.

Keywords: $\quad$ Photography - Representation. Document. Objects - Representation. Jorge Amado.

\section{REFERÊNCIAS}

ALVARENGA, Lídia. Representação do conhecimento na perspectiva da Ciência da Informação em tempo e espaço digitais. Encontros Bibli: Revista Eletrônica em Biblioteconomia e Ciência da Informação, Florianópolis, v. 8, n. 15, p. 18-40, $1^{\circ}$ sem. 2003.

AMADO, Jorge. Navegação de cabotagem: apontamentos para um livro de memórias que jamais escreverei. Rio de Janeiro: Record, 1992.

AMADO, Paloma Jorge. Rua Alagoinhas 33, Rio Vermelho. In: Rua Alagoinhas 33, Rio Vermelho: a casa de Zélia e Jorge Amado. Textos de Jorge Amado, Gilberbert Chaves e Paloma Jorge Amado. Fotos de Adenor Gondim. Arte de Pedro Costa. Salvador: Fundação Casa de Jorge Amado, 1999. p. 124-131.
AMADO, Jorge. Bahia de Todos os Santos: guia de ruas e mistérios. Desenhos de Carlos Bastos. 34. ed. São Paulo: Record, 1986.

AMADO, Jorge. Bahia de Todos os Santos: guia de ruas e mistérios. São Paulo: Companhia das Letras, 2012. Posfácio de Paloma Amado. Fotografias de Flavio Damm.

ANDRADE, Maria Eugenia Albino. Um olhar sobre representações no universo do conhecimento: o caso de micro e pequenas empresas. In: NAVES, Madalena Martins Lopes;

KURAMOTO, Hélio (Org.). Organização da informação: princípios e tendências, Brasília, DF: Briquet de Lemos/Livros, 2006. p. 22-35. 
AUMONT, Jacques. A imagem. Tradução de Estela dos Santos Abreu e Cláudio Cesar Santoro. Campinas, SP: Papirus, 1993.

BACHELARD, Gastón. A poética do espaço. Tradução de Antonio de Pádua Danesi. São Paulo: Martins Fontes, 2008.

BERGER, John. Modos de ver. Tradução de Lúcia Olinto. Rio de Janeiro: Rocco, 1999.

BOURDIEU, Pierre. A distinção: crítica social do julgamento. Tradução de Daniela Kernet al. São Paulo: Edusp; Porto Alegre: Zouk, 2008.

BOURDIEU, Pierre et al. Un art moyen: essay sur les usagessociaux de la photographie. 2 ed. Paris: Les EditionsMinuit, [2003].

BRIET, Suzanne. Qu'est-ce que la documentation?Paris: ÉditionsDocumentaires, IndustriellesetTechniques, 1951.

BUCCERONI, Claudia; PINHEIRO, Lena Vânia Ribeiro. A imagem fotográfica como documento: desideratos de Otlet. In: ENCONTRO NACIONAL DE PESQUISA EM CIÊNCIA DA INFORMAÇÃO, 10., 2009, João Pessoa. Anais... João Pessoa, 2009. p. 1-16.

BUCKLAND, Michael. Information as thing. Journalofthe American SocietyofInformation Science, Maryland, USA, v. 42, n. 5, p. 351-360, June 1991.

BUCKLAND, Michael. Whatis a document? Journal of the American Society of InformationScience, Maryland, USA, v. 48, n. 9, p. 804-809, Sept. 1997.

CARVALHO, Maria do Socorro Silva. Imagens de um tempo em movimento: cinema e cultura na Bahia nos anos JK (1956-1961). 1992. Dissertação (Mestrado) - Faculdade de Filosofia e Ciências Humanas, Universidade Federal da Bahia, Salvador, 1992.

CURRÁS, Emília. Ontologias, taxonomias em teoria de sistemas e sistemática. Tradução Jaime Robredo. Brasília, DF: Thesaurus, 2010.

DIDI-HUBERMAN, Georges. A imagem sobrevivente: história da arte e tempo dos fantasmas segundo AbyWarburg. Tradução Vera Ribeiro. Rio de Janeiro: Contraponto; Museu de Arte do Rio, 2013. (ArteFísil)

FLUSSER, Vilém. Filosofia da caixa preta: ensaios para uma futura filosofia da fotografia. São Paulo: Annablume, 2011. (Comunicações).

FRANCASTEL, Pierre. A realidade figurativa: elementos estruturais de sociologia da arte. Tradução de Mary Amazonas Leite de Barros. São Paulo: Perspectiva: Ed. USP, 1982.

GATTAI, Zélia. A casa do Rio Vermelho. 3. ed. Rio de Janeiro: Record, 1999.

GATTAI, Zélia. Floriano Teixeira. In: GATTAI, Zélia. A casa do Rio Vermelho. 3. ed. Rio de Janeiro: Record, 1999.

GATTAI, Zélia. Memorial do amor. Rio de Janeiro: Record, 2004.

GIL, Fernando. Representar. In: ENCICLOPÉDIA Einaudi. Lisboa: Imprensa Nacional, Casa da Moeda, 2000. p. 11-51. (Conhecimento, v. 41)

LE GOFF, Jacques. História e memória. Tradução de Irene Ferreira; Bernardo Leitão; Suzana Ferreira Borges. 5. ed. Campinas, SP: Ed. da UNICAMP, 2003.

LE GOFF, Jacques. Documento/Monumento, In: História e memória. Tradução de Irene Ferreira; 
Bernardo Leitão; Suzana Ferreira Borges. 5. ed. Campinas, SP: Ed. da UNICAMP, 2003.

GOMBRICH, Ernst Hans. Arte e ilusão: um estudo da psicologia da representação pictórica. Tradução Raul de Sá Barbosa. São Paulo: Martins Fontes, 1986.

MANINI, Miriam Paula. Análise documentária de fotografias: um referencial de leitura de imagens fotográficas para fins documentários. 2002. Tese (Doutorado em Ciências da Comunicação) - Departamento de Biblioteconomia e Documentação, Escola de Comunicações e Artes, Universidade de São Paulo, São Paulo, 2002.

MANINI, Miriam Paula. Imagem, memória e informação: um tripé para o documento fotográfico. Domínios da Imagem, Londrina, PR, ano IV, n. 8, p. 77-88, maio 2012.

NOVO, Hildenise Ferreira. Representação do conhecimento ou representação conceitual? Uma investigação epistemológica no âmbito da Ciência da informação e da Filosofia nas considerações de Deleuze e Guatarri. PontodeAcesso, Salvador, v. 7, n. 3, p. 114-129, dez. 2013.

OTLET, Paul. El tratado de documentación: el libro sobre el libro: teoría y práctica. Traducción Maria Dolores Ayuso García. [Murcia: Universidad de Murcia], 1996.

PESAVENTO, Sandra Jatahy. História \& historia cultural. 2. ed. Belo Horizonte: Autêntica, 2005. (Reflexões, 5)

PRANDI, Reginaldo. Religião e sincretismo em Jorge Amado. In: SCHWARCZ, Lilia Moritz; GOLDSTEIN, IlanaSeltzer (Org.). O universo de Jorge Amado. São Paulo: Companhia das Letras, 2009. v. 1, p. 46-61 Disponívelem:<http:// www.jorgeamado.com.br/professores2/05.pdf $>$ Acesso em: 9 set. 2016.
RICOUER, Paul.Tempo e narrativa. Campinas, SP: Papirus, 1994-1997. 3 v.

ROUILLÉ, André. A fotografia: entre documento e arte contemporânea. Tradução de ConstanciaEgrejas. São Paulo: Ed. SENAC São Paulo, 2009.

RUA Alagoinhas 33, Rio Vermelho: a casa de Zélia e Jorge Amado. Textos de Jorge Amado, Gilberbert Chaves e Paloma Jorge Amado. Fotos de Adenor Gondim. Arte de Pedro Costa. Salvador: Fundação Casa de Jorge Amado, 1999.

RUBIM, Albino Canelas. Partido comunista, cultura e literatura brasileira. In: DUARTE, Eduardo de Assis (Org.). Graciliano revisitado: coletânea e ensaio. Natal: Editora Universitária, 1995. v. 1, p. 203-227

SÁ, Alzira Tude de. A Bahia de Jorge Amado, a Bahia de tantos outros: visões imaginárias de uma terra prometida. In: SERAFIM, José Francisco; TOUTAIN, Lídia Brandão;

GEOFFROY, Yannick (Org.). Perspectivas em informação visual: cultura, percepção e representação. Salvador: EDUFBA, 2010. p. 187205.

SAMAIN, Etienne (Org.). Como pensam as imagens. Campinas, SP: Ed. da UNICAMP, 2012.

SAMAIN, Etienne (Org.). O fotográfico. 2. ed. São Paulo: Hucitec, 1998.

SCHAEFFER, Jean-Marie. A imagem precária: sobre o dispositivo fotográfico. Tradução Eleonora Bottmann. Campinas, SP: Papirus, 1996. (Campo Imagético).

SONTAG, Susan. Na caverna de Platão. In: SONTAG, Susan. Ensaios sobre a fotografia. 2. ed. Rio de Janeiro: Arbor, 1981. 
TARDY, Cécile. Garder trace de VEIGA, Benedito. Dona Flor e as artes da Bahia. l'exposition: lesusa gesmé moriel sdudis In: VEIGA, Benedito. Dona Flor da cidade da positif photographhique. In: JOURNÉES Bahia: ensaios sobre a memória da vida cultural SCIENTIFIQUES INTERNACIONALES DU baiana. Rio de Janeiro: 7Letras; Salvador: Casa de RÉSEAU MUSSI, 3., 2016, Toulouse. Annales... Palavras: Fapesb, 2006.

Toulouse: ENFA, 2016. p. 247-262 